\title{
РАЗВИТИЕ ИНФОРМАЦИОННЫХ ТЕХНОЛОГИЙ ХХІ ВВ. КАК ИНСТРУМЕНТ ЦИФРОВИЗАЦИИ БУХГАЛТЕРСКОГО УЧЕТА
}

\section{DEVELOPMENT OF INFORMATION TECHNOLOGIES FOR THE TWENTY- FIRST CENTURY. AS AN ACCOUNTING DIGITALIZATION TOOL}

\section{Gulumyan}

Summary: Currently, the whole world is moving along the path of the "digital revolution," penetrating into all spheres and processes of society, including financial statements. This article will consider artificial intelligence, robotization processes, which are everywhere introduced into accounting to simplify the effective conduct of internal work of the organization, excluding human errors and minimizing the cost of hiring employees. The article conducted a study of the use of digital technologies in the compilation and transfer of reports in foreign countries in comparison with Russian experience.

Keywords: accounting, financial reporting, information collection and analysis, digital economy, artificial intelligence, digital technologies, robotization, RBA technology, ERP system, RPA platform.
$\mathrm{B}$ настоящее время бухгалтерская и аудиторская виды деятельности подобно другим сегментам рынка труда находятся на стадии постепенного освоения и внедрения новых цифровых технологий. Огромную роль в современном обществе играет наличие информации, что прекрасно иллюстрирует известное изречение Натана Ротшильда «Кто владеет информацией, тот владеет миром». Развитие экономики, информационных технологий и систем позволяет компаниям быстро выходить на мировой рынок, но, чтобы стать эффективным участником нужна мощная информационная поддержка. Такой поддержкой стали международные стандарты финансовой отчётности, позволяющие представлять экономическую информацию об отдельно взятых организациях в стандартной форме, обеспечивающей, как минимум её сопоставимость. Это в свою очередь позволило повысить качество принимаемых на её основе экономических решений. Информация становится стратегическим ресурсом организации и играет важную роль в её деятельности. Данные бухгалтерской (финансовой) отчетности могут рассказать знающим людям многие тайны, поэтому в цифровой экономике значительная роль отводится и безопасности данных.

Основным направлением современных технологий является поиск рационального решения объединяя раз-
Гюлумян Давид Самвелович

аспирант, Российский экономический университет им. Г.В. Плеханова (Москва) gulum88@bk.ru

Аннотация: В настоящее время весь мир движется по пути «цифровой революции», проникающей во все сферы и процессы общества, в том числе и в бухгалтерскую финансовую отчетность. В данной статье будет рассмотрены процессы искусственного интеллекта, роботизации, которые повсеместно внедряются в бухгалтерский учет для упрощения эффективного ведения внутренней работы организации, исключая ошибки человека и минимизируя затраты по найму сотрудников. В статье проведено исследование использования цифровых технологий в составлении и передаче отчетности в зарубежных странах в сравнении с российским опытом.

Ключевые слова: бухгалтерский учет, финансовая отчетность, сбор и анализ информации, цифровая экономика, искусственный интеллект, цифровые технологии, роботизация, технология RBA, ERP система, платформа RPA.

ные концептуально разные системы в одну с возможностью ее дальнейшего применения. Определенно эта концепция должна быть применима к полному автоматизированному процессу [1].

Явным примером такой технологии можно представить процесс создания и использования программных роботов и искусственного интеллекта в бизнес-процессах по автоматизации и модернизации на предприятиях, которую так же в практике называют RBA.

Первым из основополагающих принципов работы данной технологии RBA является производство и создание программных роботов, по аналогии обычным людям, которым поставлены те же задачи. Передовым преимуществом является автоматизированный обмен информацией между разными системами, в то время как сотруднику приходиться постоянно копировать данные и информацию с последующей передачей в другие части системы, что является рутинным и не эффективным занятием.

После внедрения определенно новых принципов и решений в сфере бухгалтерского учета наибольшая часть компаний начали искать возможность автоматизировать не только сами бизнес-процессы по бухгалтерии, 
но и перевести в автоматизированный режим договорную деятельность предприятия.

Достижением настоящих научных исследований в сфере информации появились информационные технологии [2]. Изменение и открытия в области информационных технологий повлекли за собой новое понятие как электронные технологии. Следом и экономические взаимоотношения при посредничестве электронных технологий вышли на новый уровень экономического взаимодействия как цифровая экономика, что и затронуло бухгалтерский учет.

Как считает ведущий аудитор организации «Deloitte» Дэн Сандерлэнд, ответом на поставленный вопрос является полная инвентаризация текущей ситуации, от задействованных в каждой компании информационных систем до определенных особенностей той информации, которую приходится использовать [3].

Например, определенные компании уже несколько лет пользуются единой информационной системой управления ресурсами (ERP), которая внедряет собственный набор функций, который индивидуально для каждой компании решает определенный набор задач, сразу в нескольких системах. Для компаний такие алгоритмы будут принципиально иными.

Применение ERP системы дает возможность внедрить одну интегрированную программу заимствуя несколько разных. Общая система позволяет управлять логистикой, запасами, дистрибуцией, обработкой, доставкой, бухгалтерским учетом и выставлением счетфактур.

Общая внедренная система безопасности, через ERP, дает возможность иметь защиту от внешним факторов и внешних атак, такие как шпионаж и хищение. Вместе с CRM-системой и системой по контрою за качеством, ERP дает наибольший уровень удовлетворенности клиентов.

Системы mySAP ERP, MySAP All-in-One и SAP BusinessOne компании SAP AG и Oracle E-Business Suite, JD Edwards и PeopleSoft Enterprise компании Oracle наиболее распространенные среди программ, которые реализуют концепцию ERP. В сферах малого и среднего бизнеса Российской Федерации первое место по использованию систем Microsoft Dynamics AX (Axapta) и NAV (Navision) [4] находится организация Microsoft.

Существуют несколько похожих систем, которые выполняют такие же функции, как и вышеописанные системные программы ERP. Например, систему 1С: Управление производственным предприятием 8.0 часть пользователей считают аналогом ERP-системой.
На рынке Российской Федерации также можно выделить системы Фрегат - Корпорация, АВА Системы. Одним из самых ярких представителей технологичных компаний в Российской Федерации является ПАО Сбер. Технологии Сбера будут применяться для упрощения жизни россиян и при создании государственной цифровой платформы, надеется премьер-министр РФ Михаил Мишустин [5]. В 2019 году были успешно завершены приемо-сдаточные испытания роботизированного участка пересчета наличности, получено три патента.

Вышеизложенное успешное испытание позволит увеличить в три раза производительность труда кассово-инкассаторских центров при пересчете банкнот.

В 2019 году был завершен пилот по доставке корреспонденции автономным офисным роботом-курьером «Глеб». Платформы Navigation-As-A-Service и Robot-AsA-Service обеспечивают роботизированные решения по логистике внутри помещений [6].

Также ПАО «Сбербанк России» провел тестирование экзоскелета ExоChair Mk3 в рамках опытного внедрения в секторе логистики и учета документов архивного центра в Томилино. Внедрение в работу данного экзоскелета позволит увеличить производительность труда всего штата архивно-логистических центров.

Невозможно не обратить внимание на эффективную платформу Robotic Process Automation (далее - RPA), которая способствует быстрому и точному выполнению однотипной работы на виртуальной машине автономных программных роботов. С помощью внедрения RPA системы в 2019 году в ПАО Сбер было автоматизировано 103 процесса и получено 2,8 млн робо-часов трудозатрат. Данный показатель равен по трудозатратам 930 сотрудникам, что позволило освободить часть денежных средств на другую важную отрасль организации.

В пилотных этапах использования RPA рост производительности сотрудников составил $27 \%$.

Исследовательская компания RPA запустила виртуальную платформу по автоматизации процессов RPA PaaS (Robotic Process Automation Platform as a Service) через систему SberCloud. Данная платформа дает возможность оснастить внешних клиентов цикличной разработкой и сопровождением алгоритмов RPA. Клиентам, использующим данную систему, нет необходимости делать начальные инвестиции в оборудование и программное оснащение - все что необходимо предоставит провайдер.

Было протестировано 4 пилот-проекта с функциями «распознающий робот» по технологии Auto Named Entity 
Recognition. Эта функция дает возможность доставать нужную информацию из отсканированных и неструктурных документов.

Это достижение 21 века предполагается в поэтапном запуске технологии RPA. Эта система автоматизации увеличивает скорость трансформации финансов и бухгалтерского учета.

Около 70\% клиентов запускают в свою компанию автоматизированную систему по финансам и бухучету c UiPath. UiPAth - программная технология, внедряемая IT-специалистами или сотрудниками компании по созданию новых алгоритмов действий уникальных RPAроботов на базе цепочек действий в бизнес-процессах компании [7].

Благодаря RPA-системе организации успешно используют RPA в финансах, для развития своих процессов, повышения уровня качества своего продукта и работы с клиентами и увеличиваю свою конкурентоспособность в отрасли. Крупная компания внедрила корпоративное обеспечение RPA, результат компании вырос сразу: через несколько месяцев после внедрения в 2017 году 650000 сэкономленных часов в более чем 200 операциях. Японская организация на данный момент опередила эти результаты, на данный момент совершив автоматизацию, сэкономила 1,1 миллиона часов и уменьшив свои расходы на 10 млрд, запланировав их снижение на 3 года.

За полгода UiPAth решила задачу по оптимизации процессов, включающая учет заплаты, экспорт и импорт базы данных в обеспечении Datev - бухгалтерского обеспечения, которое используют бухгалтеры и консультанты налоговой в Германии, и SAP. Уровень автоматизации и ROI вышел на уровень 75\% в период за 5 месяцев, за это время организация сократила уровень допускаемых ошибок бизнес-процессов до 0, работу сотрудников, исполняемую вручную до 25\% и затачиваемое время на обработку до 65\% [8].

Компании партнеры сети данного вендора, включают в себя такие масштабные компании как PWC, KPMG, Deloitte и Accenture.

Автоматизация процессов позволяет более выгодно обеспечивать производительность, делать все более точно и быстро. RPA помогает не только сэкономить средства, но и позволяет тратить время на перемещение, проверку и размещение всех данных между каждой системой вручную.

RPA-система для организаций UiPath создает оптическое распознавание набора символов (OCR) и инструменты NLP, задействует автоматизированные процессы с функцией обработки структурных содержаний в фактурах, оцифровке естественного языка из почты и прочих документов. К общим функциям OCR и NLP, появляется функция автоматического обучения, которые позволяют использовать новые функции в операциях F\&A.

На примере ОАО «Российские железные дороги» можно рассмотреть внедрение данной системы. Основной задачей является в уменьшении времени на создание и заполнение документов, оптимизация оборота всех документов с партнерами и запросы от пользователей сети РЖД. Уменьшить часть рутинных и простых операций, которые совершает сотрудник. Когда реализовали данный проект то на 1 квартал 2020 года было внедрено около 128 автоматизированных процессов по нивелированию рутинных операций. Время на исполнение сократилось на 70\%. Робот, который был разработкой для введения информации в таблицу с тарифами стоимости АСУ «Экспресс» в пригороде, тратится на операцию около 75 минут, в то время как сотрудник на это действие тратил в среднем 268 минут. Это время уходило на регистрацию нового пользователя, введение данных по пользователю, изменение текущей информации и прочие функции, сокращение составило с 15 минут до 4 минут. Время на обработку запроса в службу поддержки с переключением на другого профильного специалиста изменилось с 5 минут до 5 секунд.

Если рассмотреть все процессы совокупно, то можно сказать, что они являются достаточно сложными, и это связано из-за регулярных изменений разных условий в самой компании, и на внешний контурах.

Д. Сандэрлэнд говорил, что для полного и эффективного использования таких технологий нужно проводить глубокий анализ каждого конкретного аспекта деятельности в каждой компании индивидуально.

Очевидный фактор в том, что процесс сбора и аналитика массива информации, технологий и системы как: ERP, RBA. RPA используют для автоматизации процессов при принятии определенных решений. Иначе, процесс сбора базы данных может использоваться только из-за наличия самих данных. Со временем мы видим, как охват этими система компаний из России и зарубежных организаций постоянно растет. 


\section{ЛИТЕРАТУРА}

1. Гутковская Е.А. Цифровая экономика, блокчейн и бухгалтерский учет. // Сб. трудов нац. науч.-практ. конф. «Современный бухгалтерский учет: проблемы и перспективы развития» (Москва, 03 апреля 2018). - М.: Российский университет транспорта. - 2018. - С. 36-43.

2. Хахонова Н.Н., Алексеева И.В., Бахтеев А.В. Бухгалтерский учет и отчетность. - М.: РИОР: ИНФРА-М, 2018. - 552 с

3. Аветова К.Г. Влияние цифровой экономики на трансформацию системы бухгалтерского учёта // Сб. трудов Межд. науч.-практ. конф. «Россия, Европа, Азия: цифровизация глобального пространства» (Ставрополь, (30 октября - 02 ноября 2018). - Ставрополь: 000 «Издательско-информационный центр «Фабула». - 2018. - С. 301-303.

4. Концепция ERP. - 07.06.2012 // Корпоративные информационные системы. - URL: https://www.sites.google.com/site/korpinfsis/home/ mezdunarodnyestandarty-planirovania-proizvodstvennyh-processov-mrp-erp sistemy (дата обращения 04.05.2020)

5. Мишустин: технологии Сбербанка используют в цифровой платформе государства. - 12.02.2020 // TACC. - URL: https://tass.ru/ ekonomika/7745103 (дата обращения 20.11.2020)

6. Годовой отчет ПАО Сбербанка 2019 г. // Сбербанк России. - URL: https://www.sberbank.com/common/img/uploaded/files/pdf/yrep/sberbank-ar19-rus.pdf (дата обращения: 10.11.2020).

7. RPA ускоряет трансформацию финансов и бухгалтерского учета. - 09.06.2018 // NFP-консалтинговая компания. - URL: https://nfp2b.ru/2018/06/09/ rpa_for_finance/ (дата обращения 20.11.2020);

8. Как РЖД роботизирует свои бизнес-процессы. Индустрия 4.0 // PБK. - URL: https://trends.rbc.ru/trends/industry/5eb2cfd49a79478bcb1f4c62 (дата 0бращения 21.11.2020).

(с Гюлумян Давид Самвелович (gulum88@bk.ru).

Журнал «Современная наука: актуальные проблемы теории и практики»

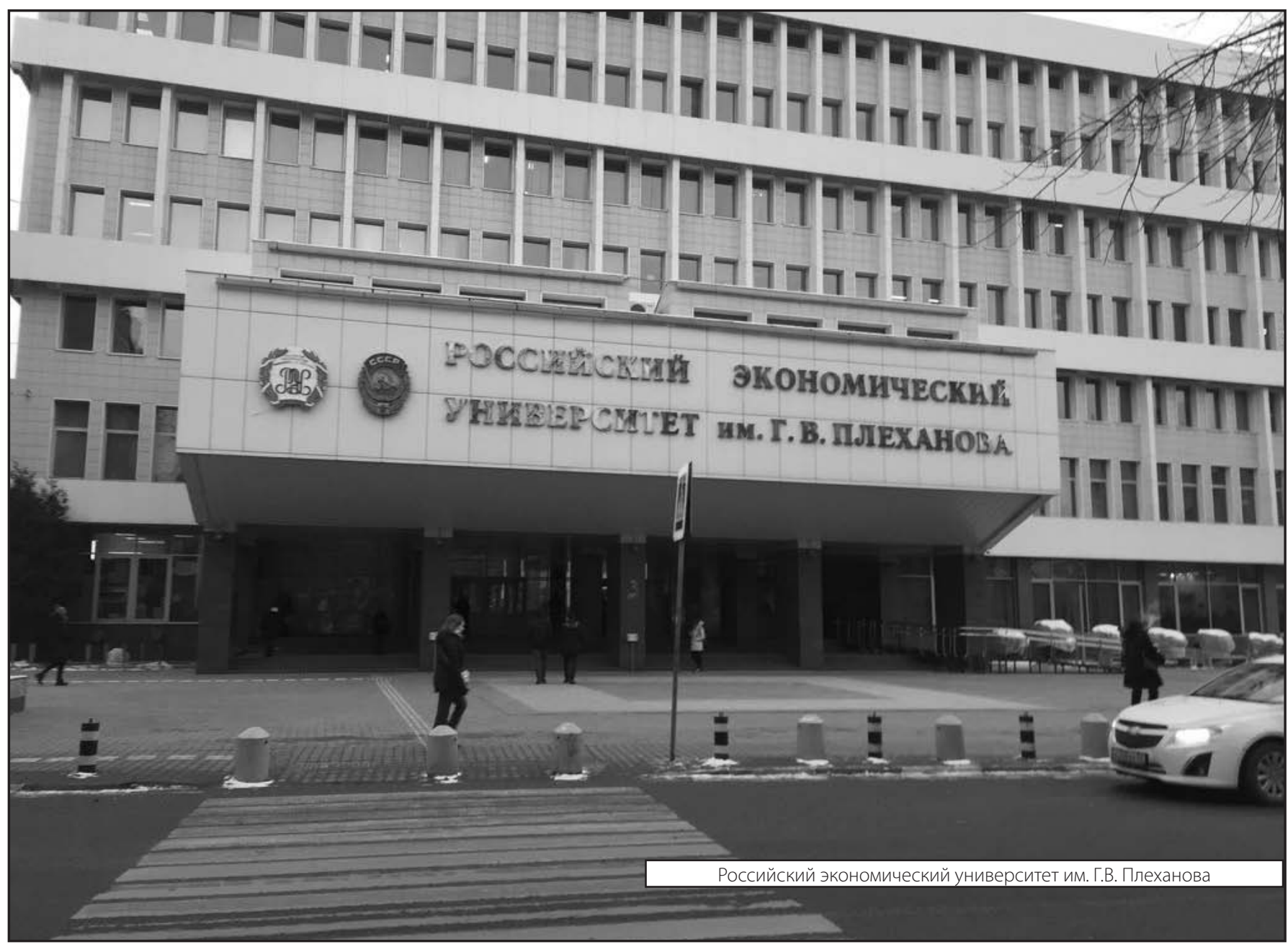

